\title{
Do overweight children consume different snacks to other children?
}

\author{
A. Courtney ${ }^{1}$, E Gibney ${ }^{2}$ and E. Feeney ${ }^{2}$ \\ ${ }^{1}$ School of Agriculture and Food Science, University College Dublin, Dublin, Republic of Ireland and ${ }^{2} U C D$ Institute of \\ Food and Health, University College Dublin, Dublin, Republic of Ireland
}

Snack consumption has been associated with increased energy intakes and weight gain ${ }^{(1)}$. Research suggests that energy-dense snack foods may be associated with different taste profiles ${ }^{(2)}$. Taste is one of the major drivers of food choice, and is a particularly important factor in children's food choice ${ }^{(3) .}$ Definitions of a snack vary, generally a snack refers to a food which is consumed outside the traditional three main meals ${ }^{(4)}$; and is not considered a substitution for a main meal ${ }^{(5)}$. The aim of this study was to identify the tastes in snack foods which are associated with energy intake, and obesity in Irish children, and whether obesity may be related to differences in the taste of snack intakes.

An existing database, the Tastebuddies study, was used here. The population sample consisted of a total of 366 school children 7 to 13 years old (205 girls; mean age 10.3 years, and 161 boys; mean age 10.5 years) from a diverse range of schools and socioeconomic backgrounds. Mean daily intakes were calculated for snack consumption, and snack foods were categorised into 'Umami', 'Salty' and 'Sweet' taste profiles. For the purpose of this study, beverages were not considered as snacks. Univariate linear models and chi-squared analysis were used to test for associations between snack intake and body weight status using SPSS for Mac (IBM).

Sweet snacks were the most highly consumed $(194 \cdot 2 \mathrm{~g}, 106 \cdot 5 \mathrm{kcal})$ snack food group overall, compared to umami $(25 \cdot 3 \mathrm{~g}, 19 \cdot 1 \mathrm{kcal})$ and salty snack foods $(18.6 \mathrm{~g}, 16.9 \mathrm{kcal})$. There was no significant difference between snack consumption (weight in grams or energy in kilocalories) and the children's weight status for any of the three taste categories.

In Ireland, school children generally have a greater consumption of sweet snacks compared to salty or umami snacks. There was no difference in the type of snack foods consumed between overweight/obese and the normal weight children, only in the volume of snacks consumed. This suggests that in this cohort of Irish children, no particular snack taste profile was associated with greater energy intake.

\begin{tabular}{|c|c|c|c|c|c|c|c|c|c|c|c|c|}
\hline \multirow[b]{3}{*}{${ }^{2}$ Weight Status } & \multicolumn{4}{|c|}{ Umami } & \multicolumn{4}{|l|}{ Salty } & \multicolumn{4}{|l|}{ Sweet } \\
\hline & \multirow[b]{2}{*}{ Mean } & \multirow[b]{2}{*}{ SD } & \multirow[b]{2}{*}{${ }^{3}$ t-stat } & \multirow[b]{2}{*}{${ }^{4} P$ Value } & \multicolumn{4}{|c|}{${ }^{1}$ Weight (g) } & \multirow[b]{2}{*}{ Mean } & \multirow[b]{2}{*}{ SD } & \multirow[b]{2}{*}{ t-stat } & \multirow[b]{2}{*}{$P$ Value } \\
\hline & & & & & $\overline{\text { Mean }}$ & SD & t-stat & $P$ Value & & & & \\
\hline Normal & $24 \cdot 4$ & $18 \cdot 2$ & & & $17 \cdot 8$ & $16 \cdot 2$ & & & 192.5 & 94.9 & & \\
\hline Overweight & 27.6 & $21 \cdot 0$ & 1.49 & $0 \cdot 137$ & $20 \cdot 6$ & 18.7 & 1.47 & $0 \cdot 144$ & $200 \cdot 1$ & 127.9 & 0.63 & 0.526 \\
\hline & & & & & Energy & & & & & & & \\
\hline Weight Status & Mean & SD & t-stat & $P$ Value & Mean & SD & t-stat & PValue & Mean & SD & t-stat & P Value \\
\hline Normal & 122.0 & 89.9 & & & $90 \cdot 2$ & 78.6 & & & $349 \cdot 7$ & $156 \cdot 1$ & & \\
\hline Overweight & 139.0 & $106 \cdot 2$ & 1.59 & $0 \cdot 113$ & $105 \cdot 7$ & $95 \cdot 1$ & 1.64 & $0 \cdot 102$ & 371.5 & $171 \cdot 3$ & 1.21 & 0.228 \\
\hline
\end{tabular}

${ }^{1}$ Weight in grams, ${ }^{2}$ Weight Status (normal weight children $(n=236)$ and overweight/obese children $(n=121)$, ${ }^{3} \mathrm{~T}-$ Statistic $($ Degrees of freedom $=355)$, ${ }^{4}$ Pvalue significant if $\mathrm{P}<0.05,{ }^{5}$ Energy in kilocalories

1. Forslund HB, Torgerson JS, Sjöström L, et al. (2005) Int J Obes 29, 711-9.

2. Maffeis C, Grezzani A, Perrone L, et al. (2008) J Ped Gast Nutr 4, 429-437.

3. Feeney E, O'Brien SA, Scannell AGM, et al. (2011) Proc Nut Soc 70, 135-143.

4. Hartmann C, Siegrist M and Van Der Horst K (2013) Pub Health Nutr 16, 1487-96.

5. Johnson GH and Anderson GH (2010) Crit Rev Food Sci Nutr 50, 848-71. 